\title{
Comparison of the Relationship between Lying and Standing Ultrasonography Measures of Muscle Morphology with Isometric and Dynamic Force Production Capabilities
}

\author{
John P. Wagle ${ }^{1, *}$, Kevin M. Carroll ${ }^{1}$, Aaron J. Cunanan ${ }^{1}$, Christopher B. Taber ${ }^{2}$, \\ Alexander Wetmore ${ }^{1}$, Garett E. Bingham ${ }^{1}$, Brad H. DeWeese ${ }^{1}$, Kimitake Sato ${ }^{1}$, \\ Charles A. Stuart ${ }^{3}$ and Michael H. Stone ${ }^{1}$ \\ 1 Center of Excellence for Sport Science and Coach Education, Department of Sport, Exercise, Recreation, \\ and Kinesiology, East Tennessee State University, Johnson City, TN 37601, USA; carrollk@etsu.edu (K.M.C.); \\ cunanan@etsu.edu (A.J.C.); wetmore@etsu.edu (A.W.); binghamg@etsu.edu (G.E.B.); \\ deweese@etsu.edu (B.H.D.); satok1@etsu.edu (K.S.); stonem@etsu.edu (M.H.S.) \\ 2 Department of Physical Therapy and Human Movement Science, Sacred Heart University, \\ Fairfield, CT 06825, USA; taberc@sacredheart.edu \\ 3 Department of Internal Medicine, Quillen College of Medicine, East Tennessee State University, \\ Johnson City, TN 37601, USA; stuartc@etsu.edu \\ * Correspondence: waglej@etsu.edu; Tel.: +1-309-230-1466
}

Received: 24 October 2017; Accepted: 14 November 2017; Published: 21 November 2017

\begin{abstract}
The purpose of the current study was (1) to examine the differences between standing and lying measures of vastus lateralis (VL), muscle thickness (MT), pennation angle (PA), and cross-sectional area (CSA) using ultrasonography; and (2) to explore the relationships between lying and standing measures with isometric and dynamic assessments of force production-specifically peak force, rate of force development (RFD), impulse, and one-repetition maximum back squat. Fourteen resistance-trained subjects (age $=26.8 \pm 4.0$ years, height $=181.4 \pm 6.0 \mathrm{~cm}$, body mass $=89.8 \pm 10.7 \mathrm{~kg}$, back squat to body mass ratio $=1.84 \pm 0.34$ ) agreed to participate. Lying and standing ultrasonography images of the right VL were collected following 48 hours of rest. Isometric squat assessments followed ultrasonography, and were performed on force platforms with data used to determine isometric peak force (IPF), as well as RFD and impulse at various time points. Forty-eight hours later, one-repetition maximum back squats were performed by each subject. Paired-samples t-tests revealed statistically significant differences between standing and lying measurements of MT $(p<0.001)$, PA $(p<0.001)$, and CSA $(p \leq 0.05)$, with standing values larger in all cases. Further, standing measures were correlated more strongly and abundantly to isometric and dynamic performance. These results suggest that if practitioners intend to gain insight into strength-power potential based on ultrasonography measurements, performing the measurement collection with the athlete in a standing posture may be preferred.
\end{abstract}

Keywords: ultrasonography; muscle architecture; force; strength; rate of force development

\section{Introduction}

Ultrasonography is commonly used to assess muscle size (e.g., muscle thickness, cross-sectional area) and architecture (e.g., pennation angle) [1-3], and has been shown to be valid against the gold standards magnetic resonance imaging [4-6] and dual energy X-ray absorptiometry [7,8]. Ultrasonography measurements are typically taken in a lying, and/or resting position, meaning that the muscle is likely evaluated in a position non-specific to upright activities. This could result in large alterations in measurements of muscle size and architecture due to the influence 
of gravity $[9,10]$. However, ultrasonography provides a level of versatility (e.g., subject positioning) that other methods do not. The adaptability of ultrasonography may be exploited to allow practitioners to develop techniques that capture muscle size and architecture in positions that maintain its functional configuration.

Muscle thickness (MT) and cross-sectional area (CSA) have previously shown moderate-to-strong relationships with magnitude of force production $(r=0.32-0.85)[10,11]$, while pennation angle (PA) has been more commonly associated with rate of force development (RFD) $(r=0.34-0.44)$ [12-14] when measurements are collected using ultrasonography. The non-specific nature of typical athlete positioning in ultrasonography assessment makes it plausible that the selected posture may influence the magnitude of relationship observed between muscle measurements and physical outputs. Ultrasonography techniques used to assess musculature as they relate to performance potential may be more appropriate if they closely reflect the positioning found in athletic maneuvers (e.g., standing). Standing assessments provide greater ecological validity, potentially yielding more precise associations between measures of muscle architecture and upright performance outcomes. To the authors' knowledge, the potential influence that subject positioning may have on the relationship between muscle function and architecture has not yet been explored.

Therefore, the purpose of the current study was (1) to examine the differences between standing and lying measures of MT, PA, and CSA using ultrasonography, and (2) to explore the relationships between lying and standing measures with isometric and dynamic assessments of force production. We hypothesized that standing measurements of muscle size and architecture would have comparatively greater relationships to such measures of physical output. This may be important for practitioners that work with athletic populations, as standing ultrasonography measurements may capture the muscle in a state that more closely represents its functional configuration.

\section{Materials and Methods}

\subsection{Muscle Size and Architecture}

Fourteen resistance-trained subjects (age $=26.8 \pm 4.0$ years, height $=181.4 \pm 6.0 \mathrm{~cm}$, body mass $=89.8 \pm 10.7 \mathrm{~kg}$, back squat to body mass ratio $=1.84 \pm 0.34$ ) volunteered for the current investigation. Subjects were required to have spent at least the past year on a resistance-training program that involved back squats. Subjects were assessed for MT, CSA, and PA of the right vastus lateralis (VL) in both lying and standing postures using ultrasonography (LOGIQ P6, General Electric Healthcare, Wauwatosa, WI, USA) [10,15]. All subjects' hydration status was determined using a refractometer (Atago, Tokyo, Japan) to ensure hydration status would not affect the ultrasound measurements [16]. Further, to ensure that there were minimal alterations in muscle size due to swelling, ultrasonography collection was performed at least $48 \mathrm{~h}$ after the most recent physical activity [17]. To determine anatomical landmark on the VL, subjects were positioned in the left lateral recumbent position with an internal knee angle of $160^{\circ} \pm 10^{\circ}$. A location half the distance between the greater trochanter and lateral epicondyle of the right femur was identified and marked. A distance $5 \mathrm{~cm}$ medial to the mid-femur marking was also identified and marked $[9,18]$. This medial marking was used for the measurement of MT. The same markings were used for both lying and standing ultrasonography measurements. All landmarks for all subjects were determined by a single practitioner, and images were collected in a repeated measures manner, and therefore any potential error would be systematic. All subjects gave informed consent, and the procedures were approved by the university's Institutional Review Board.

\subsection{Lying Cross-Sectional Area Measurement}

Lying ultrasonography measures began with the application of a water-soluble transmission gel to the measurement site and a $16 \mathrm{~Hz}$ probe oriented in the short-axis, perpendicular to the VL muscle, while not depressing the skin [19]. Lying cross-sectional area (LCSA) was obtained using a 
panoramic image sweep in the transverse plane perpendicular to the muscle [9]. A straight-edge was placed along the skin to ensure that the probe remained along the previously established midline. Three images were obtained and saved for subsequent analysis using the software provided within the ultrasonography device $[10,18]$.

\subsection{Lying Muscle Thickness and Pennation Angle Measurement}

The measurement site location for MT and PA measurement was the point $5 \mathrm{~cm}$ medial to the mid-femur mark. The ultrasonography probe was then placed in the long axis, oriented parallel to the VL muscle. The probe was held at a $90^{\circ}$ angle to the skin surface to maintain consistent images across subjects. Consistent with CSA measurement, three images were captured and saved for subsequent analysis to determine lying muscle thickness (LMT) and lying pennation angle (LPA). Analysis was performed using the software provided within the ultrasonography device $[10,18]$.

\subsection{Standing Ultrasonography Measurement}

Following lying measures of LMT, LPA, and LCSA, standing measurements of muscle thickness (SMT), pennation angle (SPA), and cross-sectional area (SCSA) were collected. These methods were consistent with lying measures with one exception: for standing measures, the subject was upright and bearing weight on the opposite leg, which was positioned on a $5 \mathrm{~cm}$ tall platform, unweighting the measured leg and creating an internal knee angle of $160^{\circ} \pm 10^{\circ}$ (Figure 1). Three separate long-axis images and three separate short-axis images were saved for subsequent analysis, the same as were used for the lying measurements [9].

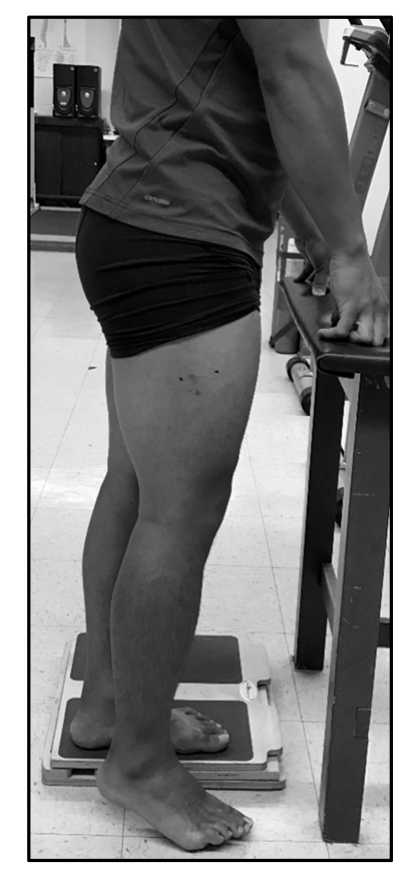

Figure 1. Standing ultrasonography collection position.

\subsection{Isometric Strength Assessment}

Subjects completed a standardized general warm-up sequence before beginning the isometric strength assessment. After completing the dynamic warm-up, participants completed one set of five repetitions of the back squat with a $20 \mathrm{~kg}$ barbell followed by three sets of five repetitions at $60 \mathrm{~kg}$, each separated by a $60 \mathrm{~s}$ rest. The isometric squat (ISQ) testing used an adapted protocol from McBride and colleagues [20,21]. Data were collected using a dual force platform design $(2 \times 91 \mathrm{~cm} \times 45.5 \mathrm{~cm}$ force platforms, RoughDeck HP, Rice Lake, WI, USA) inside a custom-built apparatus, with data 
sampled at $1000 \mathrm{~Hz}$. Participants' bar height was set on an individual basis, to the point allowing the subject to have an internal knee angle of $100^{\circ}$, which was assessed using a goniometer (Figure 2) [20].

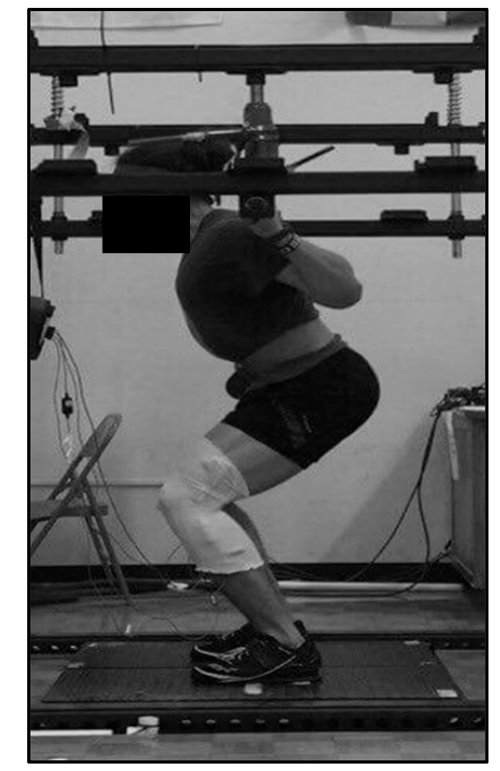

Figure 2. Isometric squat testing position.

Following bar-height adjustments, participants executed ISQ trials at 50\% and $75 \%$ of their perceived maximal effort. Each subject performed a minimum of two maximal effort trials. If a countermovement of greater than $200 \mathrm{~N}$ was observed, or trials differed by more than $250 \mathrm{~N}$, subjects were required to complete an additional trial [22]. When executing maximal effort trials, subjects were first instructed to apply steady pressure on the bar before imparting maximal effort to reduce the likelihood of a countermovement. Participants were further instructed to push 'as fast and hard as possible' and strongly verbally encouraged during trials [20,22]. A three-minute seated rest interval was prescribed between each of the ISQ trials. LabVIEW (Version 7.1, National Instruments, Austin, TX, USA) was used for collecting and ForceDecks (Version 1.2.6464, NMP Technologies Ltd., London, UK) for processing kinetic data [23]. Isometric peak force (IPF), rate of force development over $50 \mathrm{~ms}$ (RFD50), $100 \mathrm{~ms}$ (RFD100), $200 \mathrm{~ms}$ (RFD200), impulse over $50 \mathrm{~ms}$ (IMP50), $100 \mathrm{~ms}$ (IMP100), and $200 \mathrm{~ms}$ (IMP200) were calculated from the collected data.

\subsection{Dynamic Strength Assessment}

Dynamic strength testing was conducted using a one-repetition maximum (1RM) back squat, aimed at establishing dynamic peak strength capabilities. Dynamic strength testing was completed $48 \mathrm{~h}$ after isometric strength assessment to allow subjects to recover from any residual effects of the previous testing [24]. Prior to testing, each subject performed a general dynamic warm-up identical to that used in ISQ testing.

Following the warm-up, the bar height and safety bar heights in the squat rack were adjusted as needed to best accommodate each subject. Subjects then performed a 1RM back squat test using a protocol modified from Suchomel and associates [25], with warm-up set intensities based on each subject's self-reported 1RM back squat (Table 1). All subjects attempted progressively heavier loads per the protocol in Table 1 until their 1RM back squat was attained. For a repetition to be considered successful, the subject's hip crease must have been below the patella at the bottom of the descent during the back squat, as verified by multiple certified strength and conditioning professionals. 
Table 1. Back squat warm-up.

\begin{tabular}{cc}
\hline Sets $\times$ Repetitions $\times$ Intensity $(\% \mathbf{1 R M})$ & Rest Interval \\
\hline $1 \% \times 5 \% \times 30 \%$ & $1 \mathrm{~min}$ \\
$1 \% \times 3 \% \times 50 \%$ & $1 \mathrm{~min}$ \\
$1 \% \times 2 \% \times 70 \%$ & $2 \mathrm{~min}$ \\
$1 \% \times 1 \% \times 80 \%$ & $3 \mathrm{~min}$ \\
$1 \% \times 1 \% \times 90 \%$ & $3 \mathrm{~min}$ \\
$1 \mathrm{RM}$ attempts & $3 \mathrm{~min}$ \\
\hline
\end{tabular}

\subsection{Statistical Analyses}

Descriptive statistics, including mean and 95\% confidence interval (CI) were calculated. Normality was evaluated for each variable using the Shapiro-Wilk assessment. Within-subject reliability for each muscle morphology variable was assessed using coefficient of variation (CV) and intraclass correlation coefficients (ICC) [26]. Due to the high reliability observed for each variable (Table 2), the average of the three images was used for statistical analysis. Good reliability was also observed for all variables considered from isometric performance testing (ICC $=0.79-1.00$ ), so the averages of two trials were used for statistical analysis. Paired-samples $t$-Tests were calculated for standing versus lying measures of the same morphological variable to determine differences between the two subject positions. Correlations between all measurements of muscle morphology and isometric and dynamic performance capabilities were calculated using Pearson's $r$. Based on the current sample size, correlation of at least 0.53 was needed to establish a statistically significant relationship. For practical significance, Pearson's $r$ values were interpreted with magnitude thresholds previously established by Hopkins [27]. Statistical analyses were performed using JASP (Version 0.8.1.2, JASP, Amsterdam, The Netherlands) and statistical significance was set at $p \leq 0.05$.

Table 2. Reliability for each muscle size and architecture variable in lying and standing postures.

\begin{tabular}{ccc}
\hline Measure & CV & ICC \\
\hline LMT & $2.03 \%$ & 0.98 \\
SMT & $1.40 \%$ & 0.99 \\
LPA & $6.65 \%$ & 0.90 \\
SPA & $6.18 \%$ & 0.84 \\
LCSA & $1.93 \%$ & 0.95 \\
SCSA & $3.63 \%$ & 0.91 \\
\hline
\end{tabular}

$\mathrm{CV}=$ coefficient of variation; $\mathrm{ICC}=$ intraclass correlation coefficient; $\mathrm{LMT}=$ lying muscle thickness; $\mathrm{SMT}=$ standing muscle thickness; LPA = lying pennation angle; SPA = standing pennation angle; LCSA = lying cross-sectional area; SCSA = standing cross-sectional area.

\section{Results}

Each variable was normally distributed according to the Shapiro-Wilk assessment. Paired-samples $t$-Tests revealed statistically significant differences between standing and lying measurements of MT $(p<0.001)$, PA $(p<0.001)$, and CSA $(p \leq 0.05)$ (Figure 3). Standing measures resulted in greater values for all variables, presented as mean $\pm 95 \%$ CI: SMT was $14.5 \% \pm 6.67 \%$ greater than LMT, SPA was $49.0 \% \pm 16.0 \%$ greater than LPA, and SCSA was $3.4 \% \pm 3.13 \%$ greater than LCSA. Additionally, standing measures related more strongly to measures of isometric and dynamic performance. The relationships between standing and lying measures of muscle morphology with isometric and dynamic performance, as well as their practical interpretation, are displayed in Table 3. 


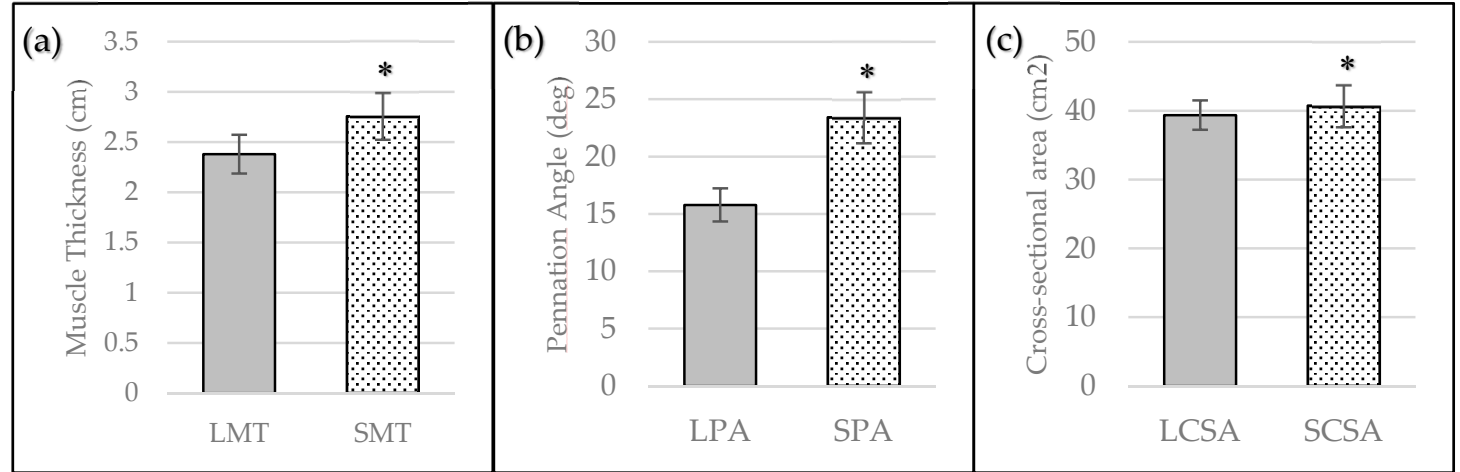

Figure 3. Lying and standing ultrasonography measurement differences for (a) Muscle Thickness; (b) Pennation Angle, and (c) Cross-Sectional Area presented as mean $\pm 95 \%$ CI. * = statistically significant difference compared to lying measure $(p \leq 0.05)$.

Table 3. Relationships between muscle size and architecture with measures of isometric and dynamic performance.

\begin{tabular}{|c|c|c|c|c|c|c|c|c|c|}
\hline Measure & Outcome & IPF & RFD50 & RFD100 & RFD200 & IMP50 & IMP100 & IMP200 & $1 \mathrm{RM}$ \\
\hline \multirow{3}{*}{ LMT } & Pearson's $r$ & 0.46 & 0.29 & 0.27 & 0.18 & 0.32 & 0.33 & 0.32 & $0.56^{*}$ \\
\hline & $p$-value & 0.10 & 0.31 & 0.35 & 0.55 & 0.26 & 0.25 & 0.26 & 0.04 \\
\hline & Interpretation & Moderate & Small & Small & Small & Moderate & Moderate & Moderate & Large \\
\hline \multirow{3}{*}{ SMT } & Pearson's $r$ & 0.73 * & $0.59 *$ & $0.53 *$ & 0.52 & $0.54 *$ & $0.58 *$ & $0.59 *$ & 0.55 * \\
\hline & $p$-value & $<0.01$ & 0.03 & 0.05 & 0.06 & 0.04 & 0.03 & 0.03 & 0.04 \\
\hline & Interpretation & Very Large & Large & Large & Large & Large & Large & Large & Large \\
\hline \multirow{3}{*}{ LPA } & Pearson's $r$ & 0.20 & -0.04 & 0.02 & -0.03 & 0.13 & 0.11 & 0.09 & 0.46 \\
\hline & $p$-value & 0.49 & 0.90 & 0.95 & 0.91 & 0.67 & 0.72 & 0.76 & 0.10 \\
\hline & Interpretation & Small & Trivial & Trivial & Trivial & Small & Small & Trivial & Moderate \\
\hline \multirow{3}{*}{ SPA } & Pearson's $r$ & 0.49 & $0.59 *$ & $0.66^{*}$ & 0.54 * & 0.38 & 0.47 & $0.53 *$ & 0.32 \\
\hline & $p$-value & 0.08 & 0.03 & 0.01 & 0.05 & 0.18 & 0.09 & 0.05 & 0.26 \\
\hline & Interpretation & Moderate & Large & Large & Large & Moderate & Moderate & Large & Moderate \\
\hline \multirow{3}{*}{ LCSA } & Pearson's $r$ & 0.38 & 0.33 & 0.25 & 0.27 & 0.52 & 0.49 & 0.44 & 0.60 * \\
\hline & $p$-value & 0.18 & 0.25 & 0.38 & 0.36 & 0.06 & 0.08 & 0.11 & 0.03 \\
\hline & Interpretation & Moderate & Moderate & Small & Small & Large & Moderate & Moderate & Large \\
\hline \multirow{3}{*}{ SCSA } & Pearson's $r$ & $0.58 *$ & 0.50 & 0.48 & 0.46 & $0.62 *$ & $0.63 *$ & $0.61 *$ & $0.77^{*}$ \\
\hline & $p$-value & 0.03 & 0.07 & 0.08 & 0.10 & 0.02 & 0.02 & 0.02 & $<0.01$ \\
\hline & Interpretation & Large & Large & Moderate & Moderate & Large & Large & Large & $\begin{array}{l}\text { Very } \\
\text { Large }\end{array}$ \\
\hline
\end{tabular}

* = statistically significant relationship ( $p \leq 0.05)$. LMT = lying muscle thickness; SMT = standing muscle thickness; LPA = lying pennation angle; SPA = standing pennation angle; LCSA = lying cross-sectional area; SCSA = standing cross-sectional area; IPF = isometric peak force; RFD50 = rate of force development at $50 \mathrm{~ms}$; RFD100 = rate of force development at $100 \mathrm{~ms}$; RFD150 = rate of force development at $150 \mathrm{~ms}$; RFD200 = rate of force development at $200 \mathrm{~ms} ;$ IMP50 = impulse at $50 \mathrm{~ms}$; IMP100 = impulse at $100 \mathrm{~ms}$; IMP150 = impulse at $150 \mathrm{~ms}$; IMP200 = impulse at $200 \mathrm{~ms} ; 1 \mathrm{RM}$ = one-repetition maximum back squat.

\section{Discussion}

The current investigation is the first study intended to determine the relationship between lying and standing measures of VL muscle morphology with upright isometric and dynamic performances. Although standing postures have been used in evaluating dynamic fascicle and tendon behavior $[17,28]$, lying muscle measurements have been commonly used when the primary interest is static muscle morphology. We hypothesized that data collected using an upright posture would provide a stronger relationship to measures of standing isometric and dynamic performance. Our results indicated that (1) collection position significantly altered ultrasonography measurements of VL muscle size and architecture, and (2) standing ultrasonography measures were more strongly and more abundantly associated with measures of upright isometric and dynamic performance compared to lying ultrasonography measures. 
Measures of standing muscle size (i.e., MT, CSA) and PA were statistically larger than the lying posture, providing evidence that body position substantially influenced the muscle measurements. Though a statistical change was found between the different postures with respect to CSA measures, there was a noticeably smaller percent difference compared to those of MT and PA. This indicates that while the measurements were quite different at the muscle belly, the measurements of whole muscle CSA were not influenced to the same degree. This may be due to a redistribution of the observed or neighboring muscle tissue and fluid between measurement positions due to gravity. Greater magnitude changes at the muscle belly may also be influenced by changes to fascicle orientation and/or rotation, creating a bulging effect [29]. Nonetheless, the observed increase in all measures of muscle morphology using an upright posture warrants an examination into the meaningfulness of such a difference. Most athletic actions are executed from standing postures, and therefore the potential exists that lying ultrasonography measures may not accurately capture the muscle in its functional configuration [30].

Lying measures yielded moderate correlations between LMT-1RM and LCSA-1RM, which is in agreement with previous findings [3,31-33]. Nevertheless, the correlations observed between standing measurements of whole muscle CSA and maximal dynamic strength were greater in magnitude, yielding a very large association between SCSA-1RM compared to a large association between LCSA-1RM. Standing CSA and SMT generated large and very large associations with IPF respectively, whereas LMT and LCSA were both considered moderate. While the relationship between muscle size as measured by ultrasonography and maximal strength has been well established [3,31-33], the results of the current investigation suggest that the selected posture in which muscle size is measured may influence the magnitude of its association with maximal strength. We speculate that this observation may be due to an underrepresentation of muscle size and architecture captured in a lying posture. When concerned with dynamic strength outcomes (i.e., 1RM), the relationship with MT was not considerably influenced by body position, as evidenced by both postures generating large correlations. The lack of influence position has on dynamic strength correlations could potentially be attributed to muscle-length changes during dynamic movements compared to isometric tests. Therefore, standing measures may better reflect muscle shape and architecture as they relate to upright isometric tests such as the isometric squat. It is possible that measurement of muscle architecture at a variety of joint angles may capture the changes in muscle length associated with changes in joint angle, thus better reflecting the changes in muscle length that occur during dynamic assessments. Practitioners may consider the positioning and nature of their physical assessment when determining the most appropriate ultrasonography technique in measuring muscle size.

Consideration of muscle architecture may give a more complete indication of the influence of body position on muscle imaging and the resulting associations with physical output. Pennation angle indicates fascicle orientation with respect to the aponeurosis and has been previously associated with both maximal strength and RFD [34,35]. The substantially larger SPA compared to LPA reflects the influence of gravity on muscle shape and resulting PA. Though the present investigation did not yield a significant relationship between SPA-IPF, the difference in relative magnitude of the relationships LPA-IPF and SPA-IPF should be noted. The difference in correlation coefficients further suggests that lying measures may not be accurately capturing muscle architecture as it relates to its maximal strength.

Maximal strength has been suggested to underpin RFD [36,37], as stronger athletes exhibit higher RFD and force at critical time points [35]. However, it may be valuable to assess RFD separately, as it has been found to correlate strongly with sport-specific tasks [38]. Muscle architecture is one of the major contributors to an athlete's RFD capabilities [39,40], along with fiber-type distribution [41-44] and efferent neural drive [35,45]. In the present investigation, SPA yielded large correlations with all of the considered spectrum of RFD time points, while lying measures yielded trivial relationships. Further, large associations were observed between SMT and all RFD time points, with only small associations observed with LMT and RFD. Rate of force development during later time intervals (i.e., $>100 \mathrm{~ms}$ ) are closely related to maximal strength [36], which may also explain the observed relationship with standing measures of muscle size. The very strong correlation with SPA may be due 
to the greater pennation angle observed, which may be due to a more compacted arrangement of series elastic elements (e.g., actin-myosin filaments, titin, cross-bridges) [46-48]. The findings of the current investigation, especially considering the relationship between SPA-RFD50, suggest that standing fiber orientation may also be considered when investigating the intrinsic muscle properties influencing early-phase RFD [35,36]. Therefore, lying measures of VL muscle architecture may misrepresent the functional configuration and RFD potential entirely, limiting ultrasonography's usefulness as a monitoring tool for strength-power athletes. Because of RFD's implication for sporting success [35], practitioners should instead consider standing measures of muscle architecture.

Impulse combines elements of magnitude and rate of force production, as increases in either would result in an increase in impulse. Impulse has well-established relationships to sprint [49-51] and change-of-direction performance [52], making it potentially the most important kinetic characteristic to consider in evaluating the overall success and potential transfer of effects resulting from a training intervention. Within the current investigation, the results suggest that standing ultrasonography measures may provide a more useful representation of VL architecture in predicting impulse potential across a range of time points. All impulse variables considered (IMP50, IMP100, IMP200) elicited statistically large associations with SMT and SCSA, but no statistical significance was reached with any lying measures of muscle size. Additionally, SPA returned substantially larger correlation magnitudes compared to LPA, further suggesting that standing measurements more accurately capture the functional configuration of VL architecture as it relates to the physical potential of strength-power athletes.

\section{Conclusions}

The results of the current investigation demonstrated that ultrasonography measurements of VL muscle size and architecture were significantly larger during standing ultrasonography imaging. This is valuable considering the desire for practitioners to capture the muscle in a state that more precisely represents its configuration during performance. Further, standing ultrasonography measures were overall more strongly associated with measures of isometric and dynamic performance. This suggests that, if practitioners intend to gain insight into strength-power potential based on ultrasonography measurements, performing collection with the athlete in a standing posture is preferred.

Acknowledgments: No funding was received for the current study.

Author Contributions: John P. Wagle, Kevin M. Carroll, and Aaron J. Cunanan carried out the experiment and wrote the manuscript. Alexander Wetmore and Garett E. Bingham assisted in carrying out the experiment and in writing the manuscript. Christopher B. Taber, Brad H. DeWeese, Kimitake Sato, Charles A. Stuart, and Michael H. Stone were instrumental in the design and implementation of the experiment.

Conflicts of Interest: The authors declare no conflict of interest.

\section{References}

1. Hodges, P.; Pengel, L.; Herbert, R.; Gandevia, S. Measurement of muscle contraction with ultrasound imaging. Muscle Nerve 2003, 27, 682-692. [CrossRef] [PubMed]

2. Miyatani, M.; Kanehisa, H.; Ito, M.; Kawakami, Y.; Fukunaga, T. The accuracy of volume estimates using ultrasound muscle thickness measurements in different muscle groups. Eur. J. Appl. Physiol. 2004, 91, 264-272. [PubMed]

3. Häkkinen, K.; Keskinen, K. Muscle cross-sectional area and voluntary force production characteristics in elite strength-and endurance-trained athletes and sprinters. Eur. J. Appl. Physiol. Occup. Physiol. 1989, 59, 215-220. [CrossRef] [PubMed]

4. Hides, J.A.; Richardson, C.A.; Jull, G.A. Magnetic resonance imaging and ultrasonography of the lumbar multifidus muscle: Comparison of two different modalities. Spine 1995, 20, 54-58. [CrossRef] [PubMed]

5. Raadsheer, M.; Van Eijden, T.; Van Spronsen, P.; Van Ginkel, F.; Kiliaridis, S.; Prahl-Andersen, B. A comparison of human masseter muscle thickness measured by ultrasonography and magnetic resonance imaging. Arch. Oral Biol. 1994, 39, 1079-1084. [CrossRef] 
6. Walton, J.; Roberts, N.; Whitehouse, G. Measurement of the quadriceps femoris muscle using magnetic resonance and ultrasound imaging. Br. J. Sports Med. 1997, 31, 59-64. [CrossRef] [PubMed]

7. Ahtiainen, J.P.; Hoffren, M.; Hulmi, J.J.; Pietikäinen, M.; Mero, A.A.; Avela, J.; Häkkinen, K. Panoramic ultrasonography is a valid method to measure changes in skeletal muscle cross-sectional area. Eur. J. Appl. Physiol. 2010, 108, 273. [CrossRef] [PubMed]

8. Dupont, A.C.; Sauerbrei, E.E.; Fenton, P.V.; Shragge, P.C.; Loeb, G.E.; Richmond, F.J. Real-time sonography to estimate muscle thickness: Comparison with mri and ct. J. Clin. Ultrasound 2001, 29, 230-236. [CrossRef] [PubMed]

9. Wells, A.J.; Fukuda, D.H.; Hoffman, J.R.; Gonzalez, A.M.; Jajtner, A.R.; Townsend, J.R.; Mangine, G.T.; Fragala, M.S.; Stout, J.R. Vastus lateralis exhibits non-homogenous adaptation to resistance training. Muscle Nerve 2014, 50, 785-793. [CrossRef] [PubMed]

10. Bazyler, C.D.; Mizuguchi, S.; Harrison, A.P.; Sato, K.; Kavanaugh, A.A.; Deweese, B.H.; Stone, M.H. Changes in muscle architecture, explosive ability, and track and field throwing performance throughout a competitive season and after a taper. J. Strength Cond. Res. 2017, 31, 2785-2793. [CrossRef] [PubMed]

11. Cormie, P.; McGuigan, M.R.; Newton, R.U. Developing maximal neuromuscular power. Sports Med. 2011, 41, 17-38. [CrossRef] [PubMed]

12. Gerstner, G.R.; Thompson, B.J.; Rosenberg, J.G.; Sobolewski, E.J.; Scharville, M.J.; Ryan, E.D. Neural and muscular contributions to the age-related reductions in rapid strength. Med. Sci. Sports Exerc. 2017, 49, 1331-1339. [CrossRef] [PubMed]

13. Maffiuletti, N.A.; Aagaard, P.; Blazevich, A.J.; Folland, J.; Tillin, N.; Duchateau, J. Rate of force development: Physiological and methodological considerations. Eur. J. Appl. Physiol. 2016, 116, 1091-1116. [CrossRef] [PubMed]

14. Zaras, N.D.; Stasinaki, A.-N.E.; Methenitis, S.K.; Krase, A.A.; Karampatsos, G.P.; Georgiadis, G.V.; Spengos, K.M.; Terzis, G.D. Rate of force development, muscle architecture, and performance in young competitive track and field throwers. J. Strength Cond. Res. 2016, 30, 81-92. [CrossRef] [PubMed]

15. Walker, S.; Blazevich, A.J.; Haff, G.G.; Tufano, J.J.; Newton, R.U.; Hakkinen, K. Greater strength gains after training with accentuated eccentric than traditional isoinertial loads in already strength-trained men. Front. Physiol. 2016, 7, 149. [CrossRef] [PubMed]

16. Oppliger, R.A.; Magnes, S.A.; Popowski, L.A.; Gisolfi, C.V. Accuracy of urine specific gravity and osmolality as indicators of hydration status. Int. J. Sport Nutr. Exerc. Metab. 2005, 15, 236-251. [CrossRef] [PubMed]

17. Damas, F.; Phillips, S.M.; Lixandrão, M.E.; Vechin, F.C.; Libardi, C.A.; Roschel, H.; Tricoli, V.; Ugrinowitsch, C. Early resistance training-induced increases in muscle cross-sectional area are concomitant with edema-induced muscle swelling. Eur. J. Appl. Physiol. 2016, 116, 49-56. [CrossRef] [PubMed]

18. Bazyler, C.D.; Mizuguchi, S.; Sole, C.J.; Suchomel, T.J.; Sato, K.; Kavanaugh, A.A.; DeWeese, B.H.; Stone, M.H. Jumping performance is preserved, but not muscle thickness in collegiate volleyball players after a taper. J. Strength Cond. Res. 2017. [CrossRef] [PubMed]

19. Prestes, J.; Tibana, R.A.; de Araujo Sousa, E.; da Cunha Nascimento, D.; de Oliveira Rocha, P.; Camarço, N.F.; de Sousa, N.M.F.; Willardson, J.M. Strength and muscular adaptations following 6 weeks of rest-pause versus traditional multiple-sets resistance training in trained subjects. J. Strength Cond. Res. 2017. [CrossRef] [PubMed]

20. McBride, J.M.; Cormie, P.; Deane, R. Isometric squat force output and muscle activity in stable and unstable conditions. J. Strength Cond. Res. 2006, 20, 915-918. [PubMed]

21. Bazyler, C.D.; Beckham, G.K.; Sato, K. The use of the isometric squat as a measure of strength and explosiveness. J. Strength Cond. Res. 2015, 29, 1386-1392. [CrossRef] [PubMed]

22. Kraska, J.M.; Ramsey, M.W.; Haff, G.G.; Frthke, N.; Sands, W.A.; Stone, M.E.; Stone, M.H. Relationship between strength characteristics and unweighted and weighted vertical jump height. Int. J. Sports Physiol. Perform. 2009, 4, 461-473. [CrossRef] [PubMed]

23. Carroll, K.M.; Wagle, J.P.; Sato, K.; DeWeese, B.H.; Mizuguchi, S.; Stone, M.H. Reliability of a commercially available and algorithm-based kinetic analysis software compared to manual-based software. Sports Biomech. 2017, 26. [CrossRef] [PubMed]

24. Bishop, P.A.; Jones, E.; Woods, A.K. Recovery from training: A brief review: Brief review. J. Strength Cond. Res. 2008, 22, 1015-1024. [CrossRef] [PubMed] 
25. Suchomel, T.J.; Sato, K.; DeWeese, B.H.; Ebben, W.P.; Stone, M.H. Potentiation effects of half-squats performed in a ballistic or nonballistic manner. J. Strength Cond. Res. 2016, 30, 1652-1660. [CrossRef] [PubMed]

26. Hopkins, W.G. Spreadsheets for analysis of validity and reliability. Sportscience 2017, 21, 36-44.

27. Hopkins, W.G.; Marshall, S.W.; Batterham, A.M.; Hanin, J. Progressive statistics for studies in sports medicine and exercise science. Med. Sci. Sports Exerc. 2009, 41, 3-13. [CrossRef] [PubMed]

28. Loram, I.D.; Maganaris, C.N.; Lakie, M. Use of ultrasound to make noninvasive in vivo measurement of continuous changes in human muscle contractile length. J. Appl. Physiol. 2006, 100, 1311-1323. [CrossRef] [PubMed]

29. Wakeling, J.M.; Randhawa, A. Transverse strains in muscle fascicles during voluntary contraction: A 2d frequency decomposition of b-mode ultrasound images. J. Biomed. Imaging 2014, 2014, 4. [CrossRef] [PubMed]

30. Drakonaki, E.; Allen, G.; Wilson, D. Ultrasound elastography for musculoskeletal applications. Br. J. Radiol. 2012, 85, 1435-1445. [CrossRef] [PubMed]

31. Fukunaga, T.; Miyatani, M.; Tachi, M.; Kouzaki, M.; Kawakami, Y.; Kanehisa, H. Muscle volume is a major determinant of joint torque in humans. Acta Physiol. 2001, 172, 249-255. [CrossRef] [PubMed]

32. Men, Y.; Young, A.; Stokes, M.; Crowe, M. The size and strength of the quadriceps muscles of old. Clin. Physiol. Funct. Imaging 1985, 5, 145-154. [CrossRef]

33. Miura, A.; Endo, M.; Sato, H.; Sato, H.; Barstow, T.J.; Fukuba, Y. Relationship between the curvature constant parameter of the power-duration curve and muscle cross-sectional area of the thigh for cycle ergometry in humans. Eur. J. Appl. Physiol. 2002, 87, 238-244. [CrossRef] [PubMed]

34. Aagaard, P.; Andersen, J.L.; Dyhre-Poulsen, P.; Leffers, A.M.; Wagner, A.; Magnusson, S.P.; Halkjær-Kristensen, J.; Simonsen, E.B. A mechanism for increased contractile strength of human pennate muscle in response to strength training: Changes in muscle architecture. J. Physiol. 2001, 534, 613-623. [CrossRef] [PubMed]

35. Andersen, L.L.; Andersen, J.L.; Zebis, M.K.; Aagaard, P. Early and late rate of force development: Differential adaptive responses to resistance training? Scand. J. Med. Sci. Sports 2010, 20, e162-e169. [CrossRef] [PubMed]

36. Andersen, L.L.; Aagaard, P. Influence of maximal muscle strength and intrinsic muscle contractile properties on contractile rate of force development. Eur. J. Appl. Physiol. 2006, 96, 46-52. [CrossRef] [PubMed]

37. Heggelund, J.; Fimland, M.S.; Helgerud, J.; Hoff, J. Maximal strength training improves work economy, rate of force development and maximal strength more than conventional strength training. Eur. J. Appl. Physiol. 2013, 113, 1565-1573. [CrossRef] [PubMed]

38. Tillin, N.A.; Pain, M.T.G.; Folland, J. Explosive force production during isometric squats correlates with athletic performance in rugby union players. J. Sports Sci. 2013, 31, 66-76. [CrossRef] [PubMed]

39. Aagaard, P. Training-induced changes in neural function. Exerc. Sport Sci. Rev. 2003, 31, 61-67. [CrossRef] [PubMed]

40. Alegre, L.M.; Jiménez, F.; Gonzalo-Orden, J.M.; Martín-Acero, R.; Aguado, X. Effects of dynamic resistance training on fascicle lengthand isometric strength. J. Sports Sci. 2006, 24, 501-508. [CrossRef] [PubMed]

41. Bottinelli, R.; Betto, R.; Schiaffino, S.; Reggiani, C. Unloaded shortening velocity and myosin heavy chain and alkali light chain isoform composition in rat skeletal muscle fibres. J. Physiol. 1994, 478, 341-349. [CrossRef] [PubMed]

42. Bottinelli, R.; Canepari, M.; Pellegrino, M.; Reggiani, C. Force-velocity properties of human skeletal muscle fibres: Myosin heavy chain isoform and temperature dependence. J. Physiol. 1996, 495, 573-586. [CrossRef] [PubMed]

43. Bottinelli, R.; Schiaffino, S.; Reggiani, C. Force-velocity relations and myosin heavy chain isoform compositions of skinned fibres from rat skeletal muscle. J. Physiol. 1991, 437, 655-672. [CrossRef] [PubMed]

44. Harridge, S.; Bottinelli, R.; Canepari, M.; Pellegrino, M.; Reggiani, C.; Esbjörnsson, M.; Saltin, B. Whole-muscle and single-fibre contractile properties and myosin heavy chain isoforms in humans. Pflüg. Arch. 1996, 432, 913-920. [CrossRef]

45. Aagaard, P.; Simonsen, E.B.; Andersen, J.L.; Magnusson, P.; Dyhre-Poulsen, P. Increased rate of force development and neural drive of human skeletal muscle following resistance training. J. Appl. Physiol. 2002, 93, 1318-1326. [CrossRef] [PubMed]

46. Blazevich, A.J.; Cannavan, D.; Horne, S.; Coleman, D.R.; Aagaard, P. Changes in muscle force-length properties affect the early rise of force in vivo. Muscle Nerve 2009, 39, 512-520. [CrossRef] [PubMed] 
47. Lieber, R.L.; Ward, S.R. Skeletal muscle design to meet functional demands. Philos. Trans. R. Soc. Lond. B 2011, 366, 1466-1476. [CrossRef] [PubMed]

48. Edman, K.; Josephson, R. Determinants of force rise time during isometric contraction of frog muscle fibres. J. Physiol. 2007, 580, 1007-1019. [CrossRef] [PubMed]

49. Hunter, J.P.; Marshall, R.N.; McNair, P.J. Relationships between ground reaction force impulse and kinematics of sprint-running acceleration. J. Appl. Biomech. 2005, 21, 31-43. [CrossRef] [PubMed]

50. Kawamori, N.; Nosaka, K.; Newton, R.U. Relationships between ground reaction impulse and sprint acceleration performance in team sport athletes. J. Strength Cond. Res. 2013, 27, 568-573. [CrossRef] [PubMed]

51. Morin, J.-B.; Edouard, P.; Samozino, P. Technical ability of force application as a determinant factor of sprint performance. Med. Sci. Sports Exerc. 2011, 43, 1680-1688. [CrossRef] [PubMed]

52. Behm, D.G.; Wahl, M.J.; Button, D.C.; Power, K.E.; Anderson, K.G. Relationship between hockey skating speed and selected performance measures. J. Strength Cond. Res. 2005, 19, 326. [PubMed]

(C) 2017 by the authors. Licensee MDPI, Basel, Switzerland. This article is an open access article distributed under the terms and conditions of the Creative Commons Attribution (CC BY) license (http:/ / creativecommons.org/licenses/by/4.0/). 